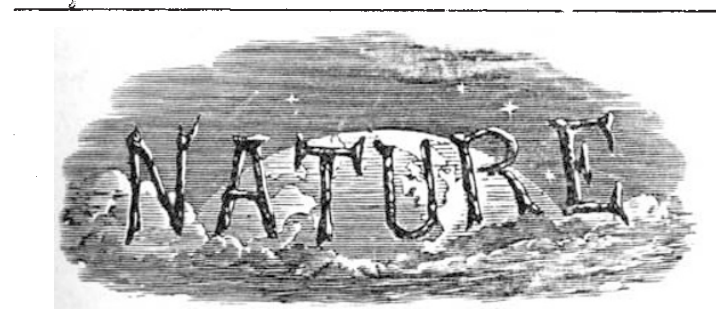

SATURDAY, APRIL I5, I922.

Editorial and Publishing Ofices :
MACMILLAN \& CO., LTD.,
ST. MARTIN'S STREET, LONDON, W.C.2.
Advertisements and business letters should be
addressed to the Publishers.
Editorial communications to the Editor.
Telegraphic Address: PHUSIS, LONDON.
Telephone Number: GERRARD 8830.

\section{Oxford and Cambridge and the Royal Commission.}

$\mathrm{T}$

$\mathrm{HE}$ original application for Parliamentary grants, which led to the appointment of the Royal Commission on Oxford and Cambridge Universities, came in I9I9 from the heads of the scientific departments of Oxford. Not only were the immediate needs stated and the provision necessary to enable work to be continued, as it had been carried on before the war, but also a great development of the departments was foreshadowed with increasing difficulties in the absence of outside assistance. The Commissioners take the view that a great opportunity has come for Oxford science greatly to strengthen its position if the University and Colleges will take determined action and if funds can be made available. Far from accepting the idea that Cambridge should be allowed to develop as a "Science" University while Oxford becomes still more pronouncedly the home of the "Humanities," the Commissioners emphasise the great value of the "juxtaposition, intellectually and socially, of the best minds in diverse subjects, and the constant interaction of the Humanities and Science on one another." Accepting this point of view completely, we propose to examine their report to see how it will help the full development of science in the two universities.

Foremost in the changes recommended by the Commissioners we place for this purpose the proposals with regard to fellowships. The development in the range and character of university studies has not been accompanied by a corresponding growth in the number of college fellowships available for distinguished teachers. At Cambridge, where on the whole the newer subjects are much more strongly placed than at Oxford, there are university professors for whom no college fellowships are available. The recommendation of the Commission to create fellowships without stipend in the colleges for senior university officersfor whose stipend the university is responsible-both meets this anomaly and leaves vacancies in college fellowships for younger teachers and researchers. Many college societies will be greatly strengthened by the additions that they will thus be able to make to their body. And here we might say that it would have been a great gain to Oxford and All Souls College alike if the Commissioners had made specific provision for the inclusion of scientific studies among those to be supported by that college. Co-ordination between the University teaching by Faculties and the college teaching by tutorial supervision will be improved under the proposed scheme. The Commissioners make very few revolutionary proposals, preferring to build on the sure foundations laid by tradition and experience, and they recognise the great value of the personal contact of the college tuition in Oxford and Cambridge. But difficulties have arisen and will arise between selfgoverning colleges choosing their own teachers and university faculties controlling departments of study, and the Commissioners have hit on a happy solution of the problem. Colleges retain their freedom to select their own staffs but are penalised financially if a fellow elected to a teaching post is not acceptable to a University Faculty for the position of University Lecturer or University Demonstrator.

Closely tied with the proposals about official fellowships is the scheme for increasing the number of unofficial research fellowships. Coupled with an increase in the number of studentships in the Universities, which would become possible if the recommendations of the Commission as to grants is adopted, this scheme will increase greatly the development of post-graduate research work in the Universities. The Commissioners rightly lay great stress on the importance of this, but point out that it must be impracticable unless the number of teachers is increased and the directors of research are freed from some of the heavy burden of routine teaching. Each proposed reform in turn falls back upon the imperative need for financial assistance : the recommendation of a grant of $100,000 \mathrm{l}$. a year to each university in place of the present grant-now become a recurring grant-of $30,000 l$. will have to be accepted before any large proportion of the Commission's proposals can be put into action.

Certain sections of the Commission's report do not deal directly with science but call for brief mention here. The present control of the University by Convocation or the Senate is to be greatly restricted. Congregation or the House of Residents-University

NO. 2737, vOL. IO9] 
and College officers-is to be the ultimate authority, its decision being checked, in the event of a strong opposing minority, by an appeal to the larger body of non-residents. A second affirmative vote by the resident body is, however, to be decisive. Unless a minority recommendation, signed by two of the Cambridge committee, calling for immediate Parliamentary action is adopted, the position of women at Cambridge is left for decision by the new House of Residents. The Commissioners do, however, support a scheme for full membership, with restriction in numbers to 500 ,-essentially scheme A rejected by the Senate in December 1920. Special grants, earmarked for the women's colleges, of 4000 . a year to each University for a period of to years should be a great help to them in their present financial difficulties and a great incentive for a renewal of appeals for benefactions from the public.

Other special grants recommended are 6000l. a year to each University for the development of the valuable extra-mural teaching, and special arrangements are suggested for allowing selected adults to join the University without passing the entrance examination to be imposed on all ordinary undergraduates. The importance of the non-collegiate body of students is emphasised as being economical, especially suitable for certain types of students and historically the oldest form of residence in both places. The minimum cost at Oxford in I920, in cheap lodgings of noncollegiate residence, including board and lodging, is given in the report as $65 l$.

A summary of the report has already appeared in our columns (April I, p. 428). It is impossible to enter here into all the important questions raised as to the cost of living and the regulations as to college finance. It is equally impossible to conclude this article without reference to the enthralling historical survey of the growth of the Universities with which the report opens.

\section{The First European Civilisation.}

The Palace of Minos: A Comparative Account of the Successive Stages of the Early Cretan Civilisation as Illustrated by the Discoveries at Knossos. By Sir Arthur Evans. Vol. I, The Neolithic and Early and Middle Minoan Ages. Pp. xxiv +72I+ I8 plates + plans, etc. (London: Macmillan and Co., Ltd., I92r.) 6 guineas.

$\mathrm{T}$ $\mathrm{HE}$ excavations at Knossos were described by Sir Arthur Evans in detailed reports which appeared in the Annual of the British School at Athens from 1900 to 1905 , and were reviewed from time to time in these columns. For years afterwards he and his adjutant, Dr. Mackenzie, were engaged in supplementary work, which involved much digging, in addition to the laboratory processes of cleaning, restoring, and classifying an enormous mass of finds. The history of successive rebuildings was unravelled, and the sequence of pottery-types verified by new trial-pits. Meanwhile discoveries on other sites have filled gaps and supplied chronological data, so that the rise of Cretan civilisation can be correlated step by step with that of Egypt. The magnificent volume before us is the first of three in which Sir Arthur Evans proposes to embody his mature conclusions; it covers two of the three main periods into which he divides the Cretan Bronze, Age, and the introduction includes an outline sketch of the whole course of Minoan culture. Much of the material, as of the interpretation, is new. The book is abundantly illustrated, with plans and sections by Mr. Theodore Fyfe and Mr. C. C. T. Doll, drawings by the two Gilliérons, Mr. Halvor Bagge, and Mr. C. T. Lambert, and many excellent photographs. Even more impressive than the extent of the excavation is the skill with which it has been carried through. One wishes that this enterprise, to which the author has so long devoted his private fortune and his unrivalled insight into prehistoric problems, had been more liberally backed by public subscription.

In a notice such as this, one can touch only on a few aspects of the story which the author unfolds. He emphasises the continuity of Cretan civilisation; "from the earliest Minoan stage to the latest there is no real break such as might be naturally explained by conquest from abroad." The Neolithic strata at Knossos are $23 \mathrm{ft}$. deep, the accumulated debris of several thousand years. If the incised pottery and nude female idols recall those of Anatolian sites, this points to a common heritage rather than to intercourse between distant tribes. Over a vast area of Europe and Western Asia the same low level of rude culture had endured for many centuries without notable progress. The sudden quickening of the Cretan stock which made their island the cradle of European civilisation, came from pre-dynastic Egypt. "It may well be asked whether, in the time of stress and change that marked the triumph of the dynastic element in the Nile Valley, some part of the older population may not have made an actual settlement on the soil of Crete "-a daring hypothesis which future discoveries may confirm; the south coast and western half of the island have been little explored and certainly hold surprises in store.

Pre-dynastic stone vases seem to have reached Knossos before the accession of Menes, for which the author accepts Eduard Meyer's date, 33도 B.c. 